\title{
Effect of Oriented Electric Fields on Biologically Relevant Iron- Sulfur Clusters: Tuning Redox Reactivity for Catalysis
}

\author{
Samuel J. H. Gaughan, Jonathan D. Hirst,* Anna K. Croft,* and Christof M. Jäger* \\ Cite This: https://doi.org/10.1021/acs.jcim.1c00791 \\ Read Online
}

ABSTRACT: Enzyme-based iron-sulfur clusters, exemplified in families such as hydrogenases, nitrogenases, and radical $S$ adenosylmethionine enzymes, feature in many essential biological processes. The functionality of biological iron-sulfur clusters extends beyond simple electron transfer, relying primarily on the redox activity of the clusters, with a remarkable diversity for different enzymes. The active-site structure and the electrostatic environment in which the cluster resides direct this redox reactivity. Oriented electric fields in enzymatic active sites can be significantly strong, and understanding the extent of their effect on

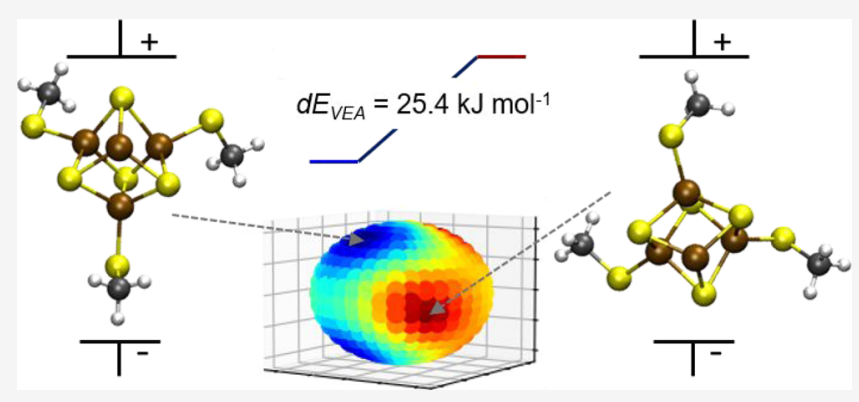
iron-sulfur cluster reactivity can inform first steps toward rationally engineering their reactivity. An extensive systematic density functional theory-based screening approach using OPBE/ TZP has afforded a simple electric field-effect representation. The results demonstrate that the orientation of an external electric field of strength $28.8 \mathrm{MV} \mathrm{cm}^{-1}$ at the center of the cluster can have a significant effect on its relative stability in the order of $35 \mathrm{~kJ} \mathrm{~mol}^{-1}$. This shows clear implications for the reactivity of iron-sulfur clusters in enzymes. The results also demonstrate that the orientation of the electric field can alter the most stable broken-symmetry state, which further has implications on the directionality of initiated electron-transfer reactions. These insights open the path for manipulating the enzymatic redox reactivity of iron-sulfur clustercontaining enzymes by rationally engineering oriented electric fields within the enzymes.

\section{INTRODUCTION}

Iron-sulfur clusters play a critical role in reactions catalyzed by several families of enzymes, providing a wide variety of functions in each. Their possible role in enabling the emergence of early life ${ }^{1}$ and capacity to perform many different roles within enzymatic pathways ${ }^{2,3}$ has led to them being characterized as "one of the most ubiquitous and functionally versatile prosthetic groups in nature". 4 The discovery and purification of ferredoxins in 1962 were an early indication that iron could play roles in enzymes in addition to its well-known presence in hemoproteins. ${ }^{5}$ Both iron and iron-sulfur clusters act primarily as mediators for electron transfer with the ability to be either the source or the sink for electrons in redox reactions, and iron-sulfur clusters are extremely useful for electron transport due to the delocalization of the electron density across the cluster. ${ }^{6,7}$ The mediator role is one of the most common functions of iron-sulfur clusters found in a variety of enzymes including those that couple proton transfer to electron transport, such as $[\mathrm{FeFe}]$ hydrogenases, which possess a unique version of an iron-sulfur cluster featuring a diiron center and a bridging dithiolate. 8,9 Many enzymes containing iron-sulfur clusters use $[2 \mathrm{Fe} 2 \mathrm{~S}],[4 \mathrm{Fe} 4 \mathrm{~S}]$, and $[3 \mathrm{Fe} 4 \mathrm{~S}]$ structures in both redox and nonredox functions. For example, radical $S$-adenosylmethionine (rSAM) enzymes make use of a [4Fe4S] cluster to reductively cleave $S$-adenosylmethionine (SAM) into methio- nine and the $5^{\prime}$-deoxyadenosyl radical, the latter of which is used to initiate a variety of radical reactions that have been reviewed previously. ${ }^{10-13}$ In some cases, electron transfer may be an intermediate step rather than the complete function of an enzyme, such as the case of the biotin synthase rSAM mechanism in which the $\mathrm{FeS}$ clusters mediate the donation of a sulfur atom. ${ }^{14}$

Redox activity is an important property in enzymes. Reengineering this property has been the focus of experimental studies for many families of enzymes, including the antioxidant peroxiredoxin, ${ }^{15}$ thioredoxins, particularly those that act as electron donors for other enzymes, ${ }^{16}$ and kinases, ${ }^{17}$ among other more general studies focused on control via thiol/ disulfide exchange, ${ }^{18,19}$ enzyme orientation, ${ }^{20}$ and substrate specificity. ${ }^{21}$ Additionally, redox activity has been used to probe the mechanism, ${ }^{2-26}$ to understand the effect of changing iron-sulfur cluster ligands on the redox potential, ${ }^{27}$ to assess the stability and reactivity of the cluster, ${ }^{28}$ and to

Received: July 6, 2021 
guide improvements in enzyme activity with directed evolution. $^{29}$

Redox reactions, often studied and used via electrochemical methods, ${ }^{30-32}$ are sensitive to electric fields. This alone would motivate an analysis of the electrostatic environment generated by an enzyme containing an iron-sulfur cluster. However, electrostatics also play a role in enzyme catalysis in general, ${ }^{33}$ including protein-protein interactions, ${ }^{34}$ conformational motions, ${ }^{35}$ and catalysis. ${ }^{36,37}$ Electrostatic preorganization in the active site of enzymes and the electrostatic stabilization associated with this are a more recent area of study. ${ }^{38}$ This preorganization has also been quantified computationally. ${ }^{39,40}$ Computational methods such as molecular dynamics simulations, density functional theory (DFT), valence bond theory, and Poisson-Boltzmann equation solvers have advanced our understanding of the role of electrostatics in enzyme catalysis, ${ }^{41-43}$ providing a more complete picture of the function of enzymes such as $\alpha$-amylase, ${ }^{44}$ methyltransferases, ${ }^{45}$ and QueE. ${ }^{46}$ These methods have also been used to study specific properties such as the contribution of individual amino acids to the overall electrostatic field of a protein, ${ }^{47}$ electrostatic steering and channeling, ${ }^{48,49}$ and the direct effect of the electrostatic field on the catalytic rate. ${ }^{50}$

The direct study of electric fields in the context of manipulating catalysis is a growing area of research. A recent review highlighted oriented electric fields as reagents, as well as their effects on enzyme catalysis. ${ }^{51}$ DFT as the quantum mechanics (QM) method in a $\mathrm{QM} /$ molecular mechanics (MM) approach has been used previously to study the effects of an electric field on biological chromophores ${ }^{52}$ and on enzymes. ${ }^{53}$ Studies have also been performed on iron-sulfur clusters in the context of enzymes to elucidate information about properties such as coordination, geometry, and electrostatics. These studies have used extended X-ray fine structure spectroscopy and DFT, ${ }^{54}$ including the application of brokensymmetry DFT $^{55}$ to iron-sulfur clusters to model antiferromagnetic coupling.

In this study, we directly and systematically investigate the impact of an external electric field on biologically relevant iron-sulfur clusters. We examine the fundamental effect of applying and reorienting a simple electric field on the stability and reactivity of selected model iron-sulfur clusters. The information on how an oriented electric field influences the reactivity of the clusters can later be combined with the knowledge and understanding of the contribution of individual amino acids to the electric field in an enzyme. This will allow the bespoke control of iron-sulfur cluster reactivity and stability through mutations of the surrounding residues. ${ }^{47}$ Consequences of these adaptations would include either the ability to improve the existing reactions by increasing the rate of reaction, integrating oxygen tolerance, or exploiting enzyme selectivity for reactions that were previously only accessible through synthetic approaches.

\section{METHODS}

Unrestricted geometry optimization calculations using DFT were performed using the Q-Chem software package ${ }^{56}$ and compared with literature values ${ }^{57}$ using the same model systems featuring the iron-sulfur clusters [2Fe2S] or [4Fe4S] and four methanethiolate ligands bound to the iron atoms, two per iron or one per iron, respectively (Figure 1). The geometry of a third cluster, identical to the $[4 \mathrm{Fe} 4 \mathrm{~S}]$ cluster but with one fewer methanethiolate ligands, was also optimized. The initial

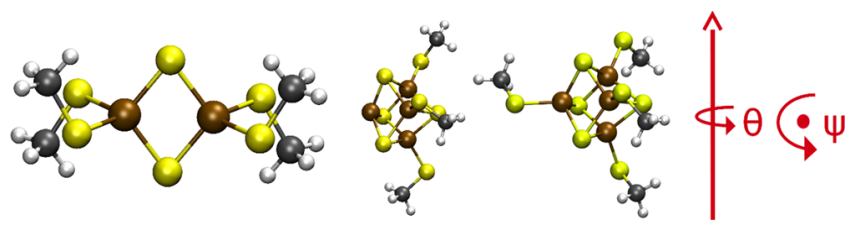

Figure 1. Definition of axes for the [2Fe2S] (left), labile [4Fe4S] (middle), and [4Fe4S] (right) clusters. All geometries shown are optimized structures for the oxidized clusters at the OPBE/TZP level of theory in a vacuum.

geometries were based on the crystal structure (PDB ID 1ZOY.) The hybrid optimized Perdew-Burke-Ernzerhof (OPBE) functional, ${ }^{58,59}$ which consists of Handy's optimized exchange (OPTX) ${ }^{60}$ and $\mathrm{PBE}^{61}$ correlation, was used for both the geometry optimizations and further single-point calculations. The use of this functional allows comparison with the work of Carvalho and Swart, ${ }^{57}$ and the spin states of the iron complexes predicted are consistent with the literature studies. ${ }^{58,59}$ The TZP basis set ${ }^{62-64}$ was chosen for both geometry optimizations and single-point calculations to facilitate this comparison. The methods used by other groups include $\mathrm{B}(5 \% \mathrm{HF}) \mathrm{P} 86$ and a triple- $\zeta$ basis set with polarization functions for accurate bond covalency ${ }^{65,66}$ and $\mathrm{B}(5 \% \mathrm{HF}) \mathrm{P} 86 /$ $6-311+\mathrm{G}(\mathrm{d})$ for the $\mathrm{QM}$ region of a $\mathrm{QM} / \mathrm{MM}$ study into the protein environmental effects around the iron-sulfur clusters. ${ }^{67}$ While these levels of theory would be suitable for optimizations, we chose OPBE/TZP because it demonstrates both the correct structural predictions and accuracy in the relative ranking of spin-state energies, which is particularly important for this study. ${ }^{68,69}$ The geometry optimizations were also repeated using the polarizable continuum model $\mathrm{COSMO}^{70}$ (conductor-like screening model) with a dielectric constant of 4.0 to simulate a protein environment. ${ }^{71,72}$

We investigate the effect of an oriented external electric field on the vertical electron affinity (VEA) and the most stable state of the model systems by performing 1296 single-point calculations in the presence of two external, equal but oppositely signed point charges, equidistant from the center of mass of the system, whose bisector intersects this center. The redox potential is an important property to consider when investigating the reactivity of iron-sulfur clusters. It is dependent on the stability difference of the oxidized and reduced states of the system and the reorganization energy. The latter is influenced by the relaxation of the system upon electron transfer and the restructuring of the environment, often dominated by solvent reorganization. The VEA accounts for the energy difference between the oxidized and reduced states without any relaxation (eq 1) and can be taken as a first approximation for the reactivity difference of the two oxidation states.

$$
E_{\mathrm{VEA}}=E_{\mathrm{ox}}-E_{\text {red }}
$$

where $E_{\mathrm{VEA}}$ is the VEA and is positive if the reduction of the oxidized state is energetically favorable, $E_{\mathrm{ox}}$ is the total electronic energy of the oxidized state, and $E_{\text {red }}$ is the corresponding energy of the reduced cluster with the oxidized cluster's geometry.

The effect of the direction of the external electric field was investigated by rotating point charges defining the field about two axes in the system and mapping them onto a sphere around the model systems. The axes of rotation used to orient the field around the clusters are shown and labeled in Figure 1. 
The notation is described further in Supporting Information Section S2.

The rotation of the electric field can be defined by the rotations about these axes. Supporting Information Section S2 provides examples of how the point charges are positioned initially and their directions of movement for all rotations applied.

Systems containing atoms with multiple possible oxidation and spin states can be described in several ways. The reduced state of the $[2 \mathrm{Fe} 2 \mathrm{~S}]$ cluster introduced earlier could have an oxidation state of +2.5 assigned to both iron atoms, a symmetrical and simplified description. In many cases, however, it is necessary to define broken-symmetry oxidation or spin states, where the additional electron might be fully localized on one of the iron atoms, for systems with ferromagnetic and antiferromagnetic coupling, for example. $^{73,74}$ This would be particularly important if a specific iron atom is involved in a reaction as the oxidation state would affect the reactivity or govern whether the reaction would progress at all.

However, it needs to be noted that Kohn-Sham DFT methods in general have limitations in describing multireference electronic systems such as the presented model iron-sulfur clusters, and we cannot easily assign formal oxidation states directly for them. To qualitatively verify the results obtained from the broken-symmetry approach, we can however conduct modified calculations to elucidate useful information and obtain electronic states that are as close as possible in energy to the true pure spin ground state. Here, restricted open-shell DFT enforces a specific spin state in situations that would otherwise require an unrestricted calculation, such as the reduced [2Fe2S] cluster which has one unpaired electron. This will result in a pure spin state that, however, will be higher in energy than the result from an unrestricted calculation on the same system. Broken-symmetry DFT (BS-DFT) ${ }^{55}$ can also be used to investigate the different broken-symmetry states for a single spin state. Using the broken-symmetry states and the maximum-spin pure spin state, we can also calculate the Heisenberg coupling constant $J$ which can provide a direct comparison to experimental results. This method is detailed in Section S6 of the Supporting Information.

There are two broken-symmetry states for the $1 / 2$ spin system, where the electron density of the unpaired electron is localized to one of the iron atoms, analogous to the system where the oxidation states of the iron atoms of the $[2 \mathrm{Fe} 2 \mathrm{~S}]$ cluster are $+2 /+3$ and $+3 /+2$. A single-point calculation using a default guess wave function for the $1 / 2$ mixed spin reduced cluster using one of the point charge positions will give one of the two broken-symmetry states. By taking the final wave function from each of these situations and using them as guess wave functions in two calculations without point charges but preserving the orbital occupancies, we calculated two wave functions, one for each broken-symmetry state, which do not have orbitals influenced by an external field. We used these wave functions as initial guesses when we added point charges, allowing us to see the full range of field effects for both brokensymmetry states. Geometry optimizations and subsequent frequency calculations were performed in vacuum and using COSMO with a dielectric of 4.0 for the model [2Fe2S], [4Fe4S], and labile 4Fe4S iron-sulfur clusters for the four reported mixed spin states in each case. ${ }^{57}$

\section{RESULTS AND DISCUSSION}

The energy relative to the calculated ground state for each system is reported in Table 1 . All optimized geometries that

Table 1. Relative Energies for OPBE/TZP GeometryOptimized-Model Iron-Sulfur Clusters in Different Spin States, Compared with the Literature Values ${ }^{57}$ in Both Vacuum and within a COSMO Environment Using a Dielectric of $4.0^{a, b}$

\begin{tabular}{|c|c|c|c|c|}
\hline \multirow{2}{*}{$\begin{array}{c}2 \mathrm{Fe} 2 \mathrm{~S} \\
\text { oxidized }\end{array}$} & \multicolumn{4}{|c|}{ mixed spin, mS } \\
\hline & $\mathrm{mS}=\mathbf{0}$ & $\mathrm{mS}=1$ & $\mathrm{mS}=2$ & $\mathrm{mS}=5$ \\
\hline reference & 0.00 & 54.34 & 104.21 & 72.64 \\
\hline vacuum & 0.00 & 65.93 & 110.44 & 84.06 \\
\hline COSMO & 0.00 & 57.44 & 100.68 & 83.69 \\
\hline reduced & $\mathrm{mS}=1 / 2$ & $\mathrm{mS}=3 / 2$ & $\mathrm{mS}=5 / 2$ & $\mathrm{mS}=9 / 2$ \\
\hline reference & 0.67 & 84.11 & 100.57 & 0.00 \\
\hline vacuum & 0.00 & 92.64 & 98.74 & 7.47 \\
\hline COSMO & 0.00 & 84.24 & 91.71 & 4.16 \\
\hline $4 \mathrm{Fe} 4 \mathrm{~S}$ & \multicolumn{4}{|c|}{ mixed spin, $\mathrm{mS}$} \\
\hline oxidized & $\mathrm{mS}=0$ & $\mathrm{mS}=1$ & $\mathrm{mS}=\mathbf{2}$ & $\mathrm{mS}=9$ \\
\hline reference & 0.00 & 48.61 & 82.94 & 156.38 \\
\hline vacuum & 0.00 & 45.99 & 81.33 & 177.29 \\
\hline COSMO & 0.00 & 44.85 & 79.85 & 181.25 \\
\hline reduced & $\mathrm{mS}=1 / 2$ & $\mathrm{mS}=3 / 2$ & $\mathrm{mS}=5 / 2$ & $\mathrm{mS}=17 / 2$ \\
\hline reference & 0.00 & 62.09 & 66.15 & 63.97 \\
\hline vacuum & 0.00 & 59.64 & 66.13 & 74.39 \\
\hline COSMO & 0.00 & $50.65^{*}$ & 61.11 & 77.45 \\
\hline labile $4 \mathrm{Fe} 4 \mathrm{~S}$ & \multicolumn{4}{|c|}{ mixed spin, $\mathrm{mS}$} \\
\hline oxidized & $\mathrm{mS}=\mathbf{0}$ & $\mathrm{mS}=1$ & $\mathrm{mS}=\mathbf{2}$ & $\mathrm{mS}=9$ \\
\hline vacuum & 0.00 & 58.45 & 53.92 & 160.14 \\
\hline COSMO & 0.00 & 56.53 & 56.28 & 163.19 \\
\hline reduced & $\mathrm{mS}=1 / 2$ & $\mathrm{mS}=3 / 2$ & $\mathrm{mS}=5 / 2$ & $\mathrm{mS}=17 / 2$ \\
\hline vacuum & 0.00 & 64.99 & 45.80 & 66.36 \\
\hline COSMO & 0.00 & 56.28 & 46.79 & 58.52 \\
\hline
\end{tabular}

${ }^{a}$ Values presented in $\mathrm{kJ} \mathrm{mol}^{-1}$. All values correspond to geometryoptimized structures at the given oxidation and mixed spin state. Absolute energy values are presented in the Supporting Information (Table S1). ${ }^{b}$ Optimized state with one imaginary frequency. This state was not used in any further calculations.

were used in later calculations were confirmed as minima by frequency calculations. The only case where the ground state is not the low spin state is from the reference value for the reduced [2Fe2S] cluster; this is not surprising as the $1 / 2$ and $9 / 2$ spin states are isoenergetic. The geometry and frequency calculations for each spin state agree with the literature values $^{57}$ within $5 \mathrm{~kJ} \mathrm{~mol}^{-1}$ (Table 1 ) and are consistent in the relative stability of each state and can therefore be justified for use in the subsequent investigations for the purpose of determining relative stability and reactivity when a directed external electric field is applied. The $\left\langle S^{2}\right\rangle$ values for these optimizations are reported in Table $S 1$ of the Supporting Information. The optimizations in a COSMO environment were generally lower in energy but showed the same trends in stability as the vacuum environment. This is to be expected as prior work found that both PCM and COSMO approaches converge to very similar structures as the gas-phase optimization, although there were some exceptions. ${ }^{75}$ COSMO has also been used in the successful prediction of Mössbauer spectral parameters, ${ }^{76}$ reduction potentials, ${ }^{77}$ and other properties of iron-sulfur clusters and similar molecules. ${ }^{78}$ Furthermore, experimental work has shown that the 
a)

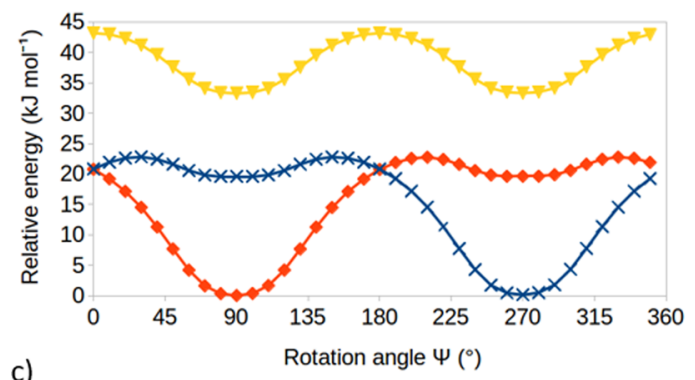

c)

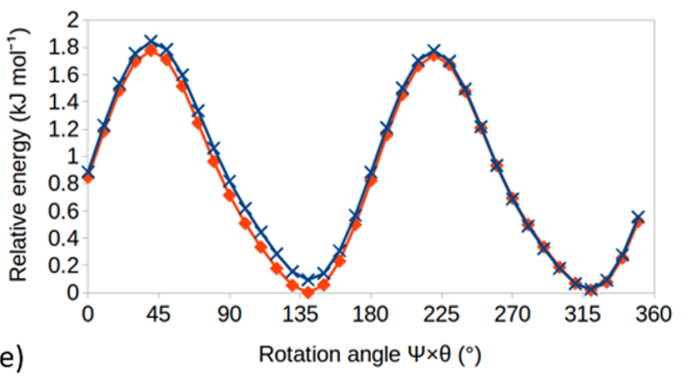

e)

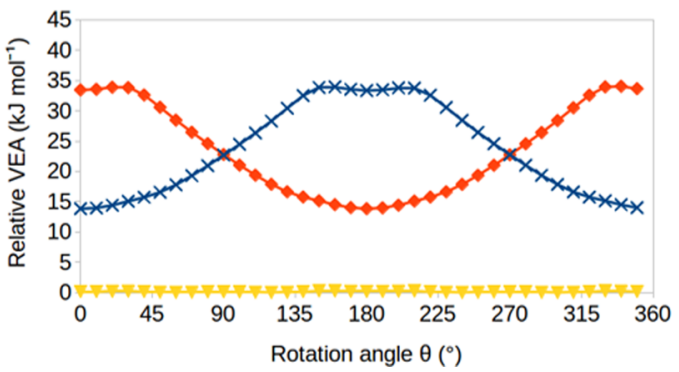

b)
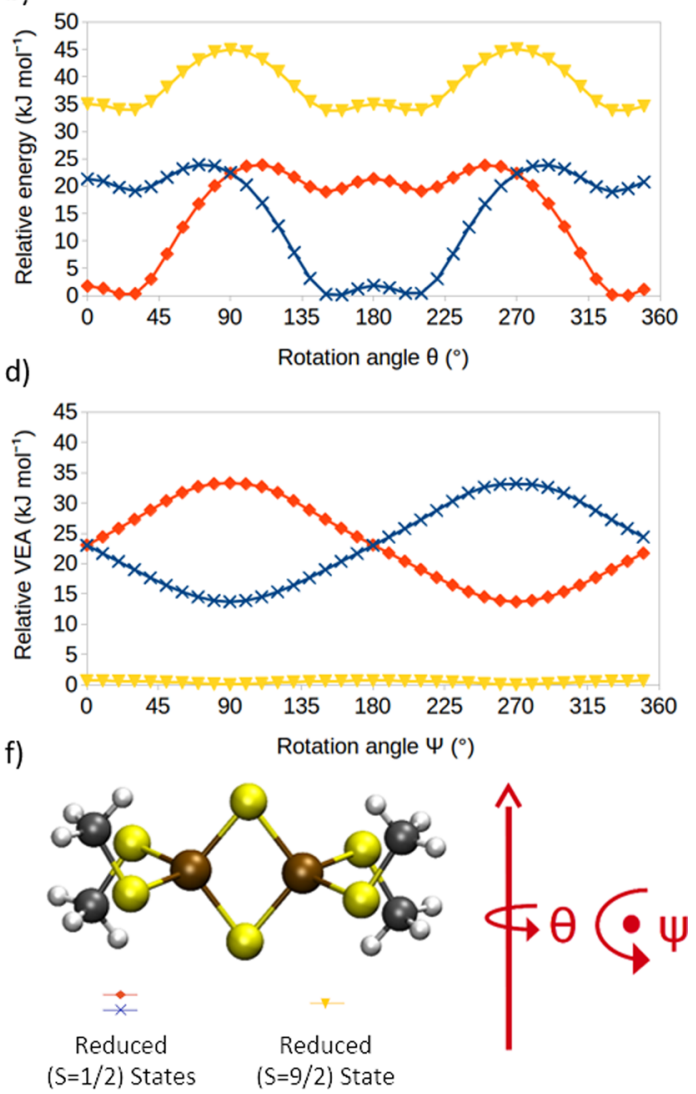

Figure 2. Relative energy profiles of the reduced [2Fe2S] model cluster $(\mathrm{a}-\mathrm{c})$ and the VEA $(\mathrm{d}, \mathrm{e})$ of the same cluster with the orientation of an external electric field in the gas phase. Rotation angle indicates the rotation from the initial position of the field about the axis normal to the plane of the cluster $(\mathrm{a}, \mathrm{d})$, the $\mathrm{S}-\mathrm{S}$ axis $(\mathrm{b}, \mathrm{e})$, or the $\mathrm{Fe}-\mathrm{Fe}$ axis $(\mathrm{c})[\psi \times \theta$ represents the rotation around the axis perpendicular to those shown in $(\mathrm{f})]$.

redox potential of biological iron-sulfur clusters is significantly dependent on the environment when considering different enzymes $^{79}$ or modifying the ligands of the cluster. ${ }^{28}$ Optimizations on the labile $[4 \mathrm{Fe} 4 \mathrm{~S}]$ cluster can also be justified using the same reasoning and could be used for further study of a similar nature when investigating the behavior of the cubane cluster where one iron atom is not bound to a ligand (e.g., SAM in the radical SAM enzyme superfamily). Using VEA as a surrogate for the redox potential is not a new approach but offers an approximation with the potential for high throughput needed to systematically study an oriented electric field effect. Previous work has gone further to approximate redox potentials from DFT calculations by considering electronegativity, ${ }^{80}$ electrophilicity, ${ }^{81-83}$ and combinations of properties. ${ }^{84,85}$ While these methods would provide more experimentally comparable values, the VEA provides a sufficient description of the change in these properties and is straightforward to compute. This makes it feasible to investigate the effect of a rotating electric field via thousands of individual single-point DFT calculations.

The relative energies are in good agreement with the literature values obtained for these systems with the order of spin-state stability preserved. Slight differences in the energies compared to the literature are likely to originate from different implementations of the implicit solvent method (COSMO) and different convergence criteria in the used programs but do not influence the qualitative agreement. Single-point calcu- lations were performed on the model iron-sulfur clusters in the presence of an electric field of varying orientation for the oxidized and reduced states. The optimized geometry of the ground-state spin oxidized cluster was used in all cases to allow the calculation of the VEA. Figure 2 displays the effect of the rotation of the electric field on the energy of the two most stable $9 / 2$ and $1 / 2$ spin states of the reduced [2Fe2S] model cluster about the principal axes presented in Figure 1.

As can be seen in Figure 2, reorienting a directed electric field can influence the electronic stability of the [2Fe2S] cluster significantly. Depending on the axis of rotation, the effect on the stability can vary up to $23 \mathrm{~kJ} \mathrm{~mol}^{-1}$ (in case of rotating around the normal to the plane of the cluster, Figure $2 \mathrm{a}, \mathrm{b}, \mathrm{e}$ ) and down to only $1.8 \mathrm{~kJ} \mathrm{~mol}^{-1}$ (in case of rotating around the Fe-Fe axis, Figure $2 \mathrm{~d}$ ). Each spin state is influenced differently in relation to the field orientation, which leads to a varying energy gap between the spin states. However, this variation is never large enough to lead to the $9 / 2$ spin state being the ground state (Figure $2 a-c$ ). When comparing the electric field effect between the gas phase (Figure 2a) and an implicit solvation with a low dielectric constant of 4.0 (Figure $2 \mathrm{~b})$, the observed effect is maintained, but the energy gap between the two spin states decreases slightly. Further results with implicit solvation are presented in Supporting Information Section S5. The $\left\langle S^{2}\right\rangle$ values for the reduced [2Fe2S] cluster $\mathrm{mS}=1 / 2$ broken-symmetry states are also discussed in Section $\mathrm{S} 1$ and Figure $\mathrm{S} 1$ of the Supporting Information, 
a)

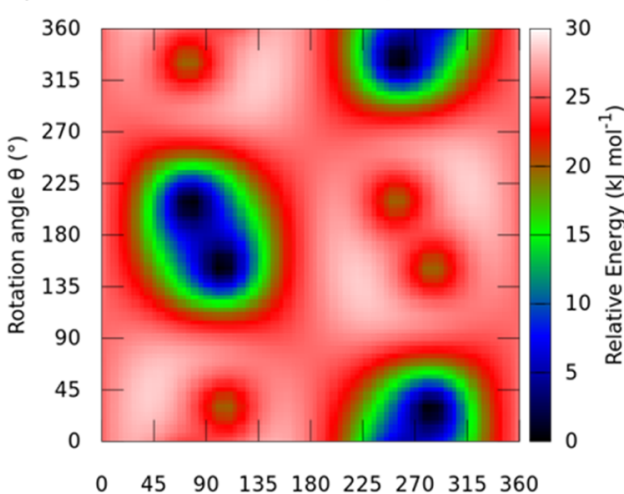

Rotation angle $\psi\left({ }^{\circ}\right)$

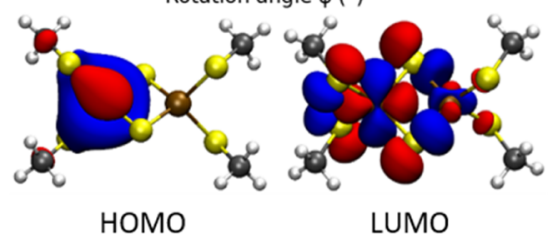

c)
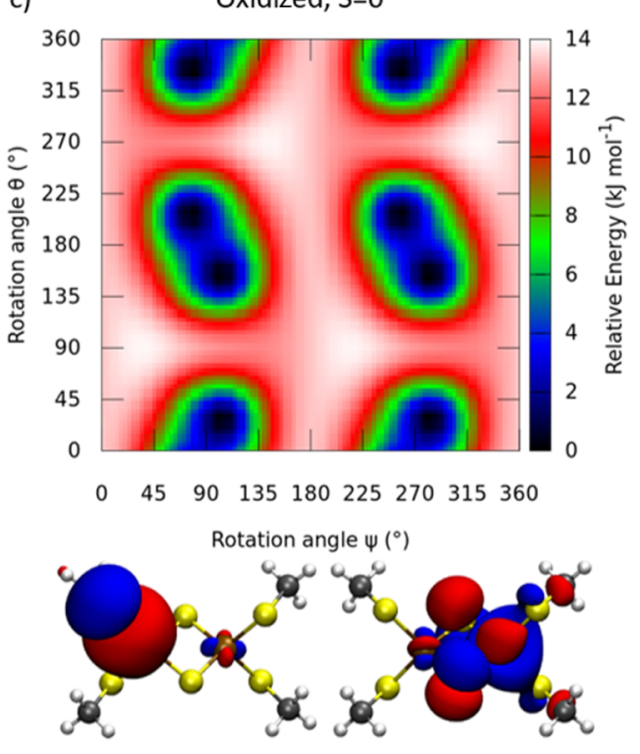

b)

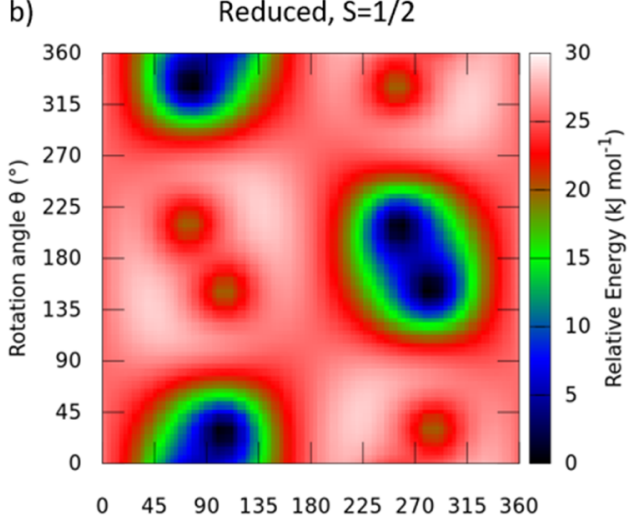

$\begin{array}{lllllllll}0 & 45 & 90 & 135 & 180 & 225 & 270 & 315 & 360\end{array}$

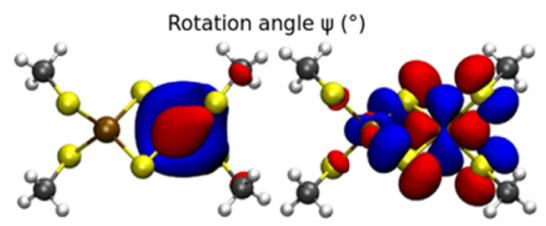

HOMO

LUMO

d)

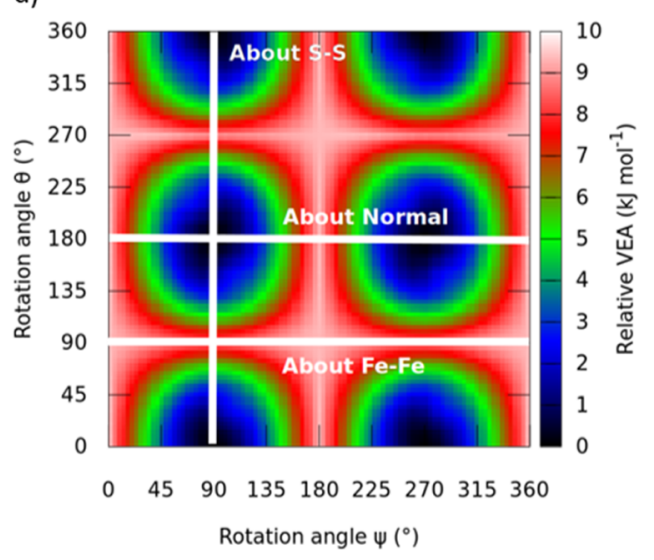

HOMO

LUMO

Figure 3. Frontier orbitals and effect of the three-dimensional rotation of an oriented electric field around the [2Fe2S] cluster. (a) Reduced, $S=1$ / 2, broken-symmetry state 1 ; (b) reduced, $S=1 / 2$, broken-symmetry state 2 ; (c) oxidized, $\mathrm{mS}=0$; (d) relative VEA with the most stable reduced broken-symmetry state.

demonstrating only minor changes in the $\left\langle S^{2}\right\rangle$ upon the rotation of the electric field around the cluster.

Next, it was investigated how the electric field influences the stability of different broken-symmetry states, which showed a significant effect on the relative stability of those. When rotating the field around the normal to the plane of the [2Fe2S] cluster (Figure 2a,b), the most stable spin state flips when the field is exactly aligned along the $S-S$ axis. This means that depending on the orientation of an external electric field, the cluster adapts by adopting a different brokensymmetry state. As these different states will show different reactivities in the directed electron transfer, notably in relation to redox potential, ${ }^{71}$ they will also show different reactivity patterns with, for example, different substrates reacting with the cluster in an enzymatic active site. The rotation about the $\mathrm{Fe}-\mathrm{Fe}$ axis is diagrammatically presented in the Supporting
Information (Figure S1). There is very little variation in VEA, with the value for the $1 / 2$ spin states remaining between about 22 and $23 \mathrm{~kJ} \mathrm{~mol}^{-1}$ and the $9 / 2$ spin state between 0 and $1 \mathrm{~kJ}$ $\mathrm{mol}^{-1}$.

The relationship between the stability of the oxidized and reduced clusters and the changes to the redox reactivity of the clusters are inferred from the VEA calculations for the cluster from the data presented above. Figure 2e depicts how the VEA varies with rotation about the normal axis. Depending on the rotation axis, $\Delta E_{\mathrm{VEA}}$ varies by up to $20 \mathrm{~kJ} \mathrm{~mol}^{-1}$. The results also suggest that the $9 / 2$ spin state of the reduced cluster is unlikely to be involved in redox reactions as it is both less stable and has a lower electron affinity than both $1 / 2$ spin states.

To extend this analysis of the principal axes of the [2Fe2S] cluster, we systematically scanned the orientation of the 


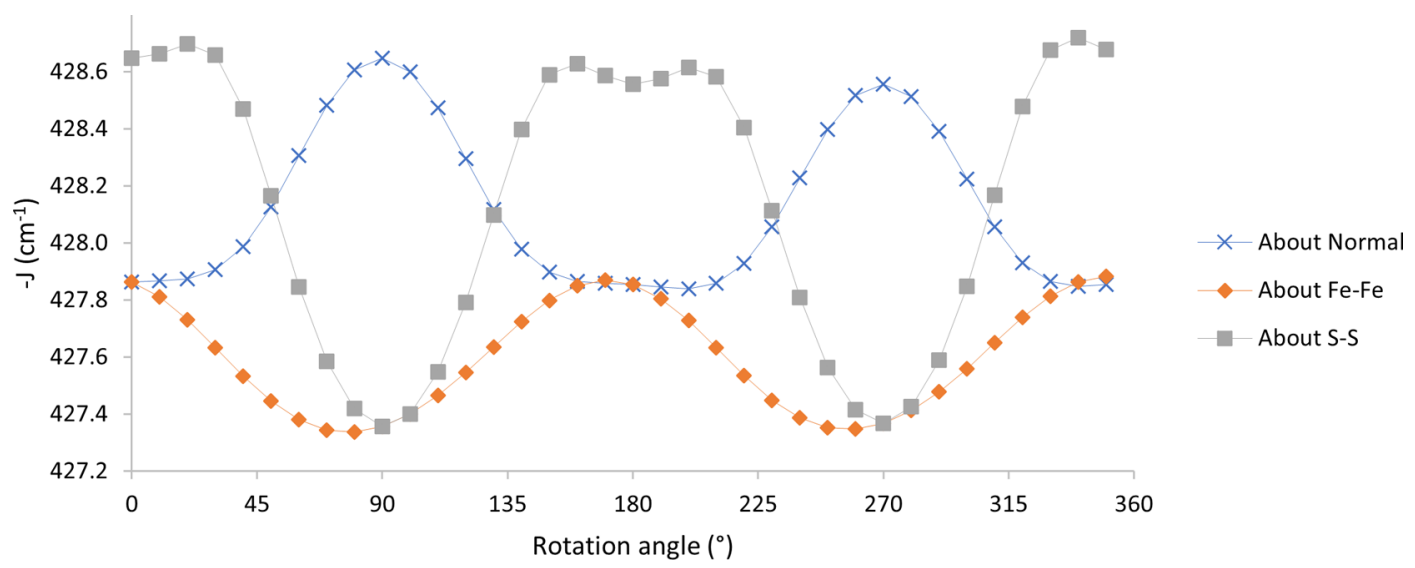

Figure 4. Effect of a rotation electric field around the three principal axes of the oxidized [2Fe2S] model cluster on the Heisenberg coupling constant $J$.

electric field about multiple axes to create a three-dimensional visualization. Figure 3 depicts the analysis for the $[2 \mathrm{Fe} 2 \mathrm{~S}]$ cluster. To understand why a differently oriented electric field influences the stability and reactivity of the [2Fe2S], we then matched these observations to the symmetry of the frontier orbitals of the reactive species.

The stability pattern observed for the principal axes' rotations described above is reflected in the analysis of the full rotations. When looking at the VEA, some electric field orientations show significantly higher reactivity compared to others. Considering the individual stabilities of the oxidized and reduced states, one can further see the relation with the frontier orbital occupancies, as also depicted in Figure 3.

Looking at the differences for the two reduced brokensymmetry spin states, the effect of the directed electric field is mirror-symmetric for each state. The cluster is stabilized when the side with the higher electron density of the highest occupied molecular orbital (HOMO) is close to the positive charge defining the electric field. Due to the different orbital occupancies of the oxidized state (fully occupied HOMO), this species shows a higher symmetry in reference to the effect of the electric field.

To validate the applicability and quality of the applied broken-symmetry approach for our investigations, we have also calculated the pure spin state energies and have derived the Heisenberg coupling constant $J$ of this system when rotating an electric field around the principal axes detailed above and as such found the effect of the electric field on the spin coupling constant $J$ (Figure 4). A detailed description of the methodology is presented in Section S6 of the Supporting Information. Overall, this analysis confirms that the profile of the energy change with a rotating electric field is the same for a pure spin state and a broken-symmetry state for these systems, with the pure spin state higher in energy. While the effect on the oxidized [2Fe2S] cluster (see Figure 4 ) only has a range of about $1.5 \mathrm{~cm}^{-1}$, it is noticeable that the magnitude of the effect is similar for all rotation axes, while the energy changes for the $\mathrm{Fe}-\mathrm{Fe}$ axis rotation were an order of magnitude smaller than the other axes. As such, the changes in energy around this axis would imply that very little about the system changes compared to other axes of rotation, but there are other quantities that will still be affected by the field direction around this axis.

The value of $J$ extracted using this method lies within the range of values reported in the literature for the same or very similar systems, noting that there seems to be a common overestimate of $J$ from the theoretical calculations compared to experimentally derived values. ${ }^{7,73,86,87}$

The cubane cluster displays more complex features. While the $[2 \mathrm{Fe} 2 \mathrm{~S}]$ cluster showed clear symmetry for the oxidized state and a clear asymmetry related to the positioning of the unpaired electron density in the reduced states, the [4Fe4S] cluster appears to display similar patterns of stability regardless of oxidation or the broken-symmetry state. The magnitude of these patterns varies, however. The relative energy of the cubane clusters with respect to the rotation of the field is influenced by the location of the HOMO seen in Figures 5 and 6. The significant change in the location of the electron density between these two broken-symmetry states results in the quadrants containing the maxima and minima being reversed. The directions of the field that result in the greatest stability remain broadly the same between these and the oxidized state. This suggests that the external electric field has a lower polarizing effect on the $[4 \mathrm{Fe} 4 \mathrm{~S}]$ cluster compared to the [2Fe2S] cluster and therefore a much lower effect on stability. Any of the four rotations where $\psi, \theta=90^{\circ}, 270^{\circ}$ show the largest degree of variation in relative energy. These rotations lie along two perpendicular internal quadrilateral planes of the cluster that are coincident with its edges. The maximum VEA difference observed for the electric field is $\Delta E_{\mathrm{VEA}}=25.4 \mathrm{~kJ}$ $\mathrm{mol}^{-1}$.

The labile cubane cluster also shows only a difference in the magnitude rather than the location of the lowest energy orientation. There is a much less complex pattern for this molecule, and noting that the points at which the field is aligned along a vector passing through the edge created by the labile iron and a sulfur atom have the highest VEA and a perpendicular vector has the lowest VEA suggests that the effect of this labile iron atom is dominant. Here, the maximal influence of the electric field on the VEA is not along an axis involving the unique iron. The maximum electric field effect on the VEA observed for this cluster is $\Delta E_{\mathrm{VEA}}=20.90 \mathrm{~kJ} \mathrm{~mol}^{-1}$. Previous work on similar ${ }^{88}$ and related ${ }^{89}$ structures shows that the values for the changes in VEA are both significant relative to the absolute VEA but not unreasonably high in magnitude. Notably, these VEA values fall within the $0-0.51 \mathrm{eV}(0-49 \mathrm{~kJ}$ $\mathrm{mol}^{-1}$ ) range of magnitudes predicted when varying the surrounding and connected amino acids around the ironsulfur clusters. ${ }^{67}$ It is also of interest to note that the field vectors resulting in the maximum and minimum values of 
a)

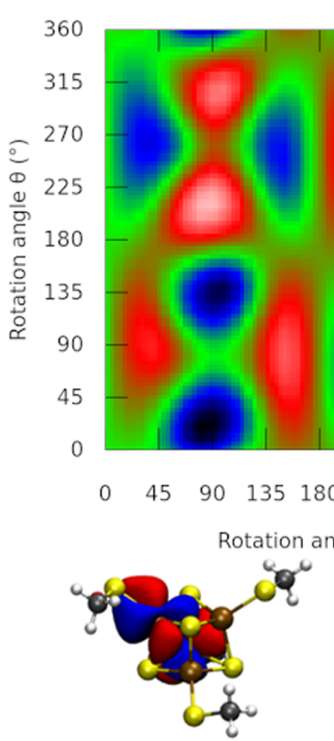

HOMO

c)

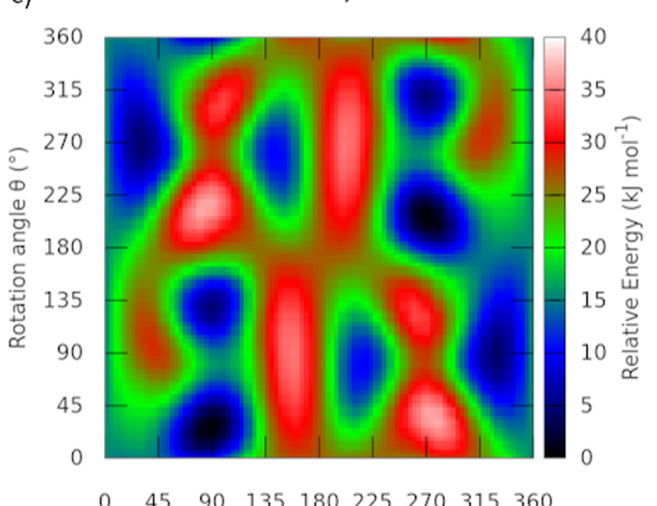

$\begin{array}{lllllllll}0 & 45 & 90 & 135 & 180 & 225 & 270 & 315 & 360\end{array}$

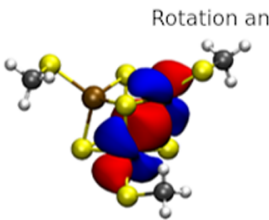

HOMO
Reduced, $S=1 / 2$
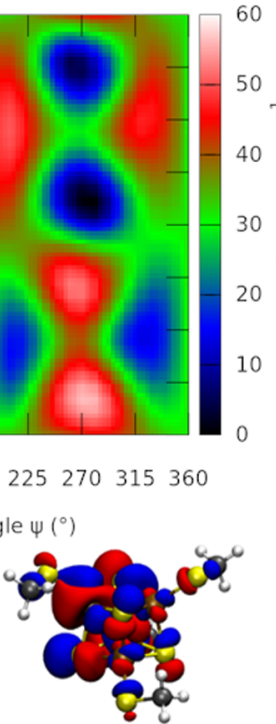

LUMO

Oxidized, $\mathrm{S}=0$ b)
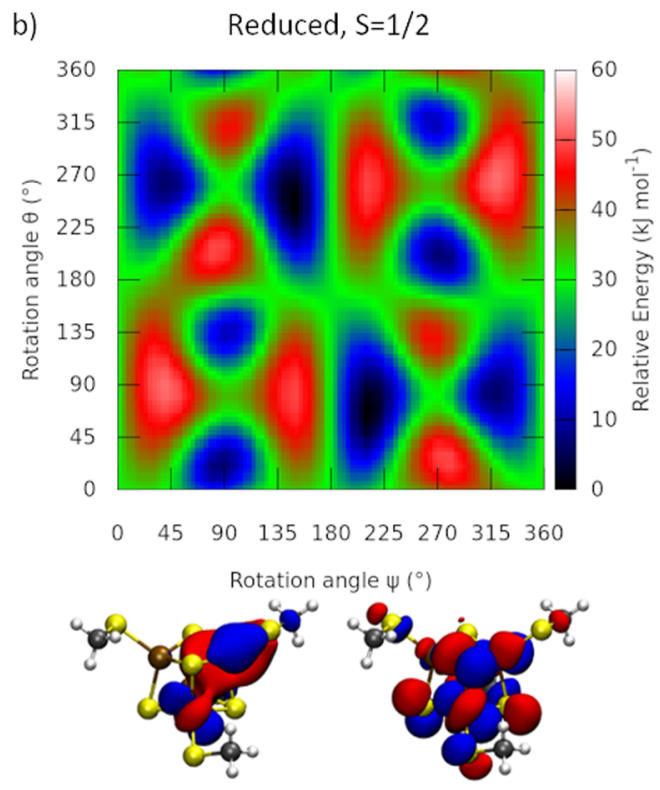

HOMO

d)

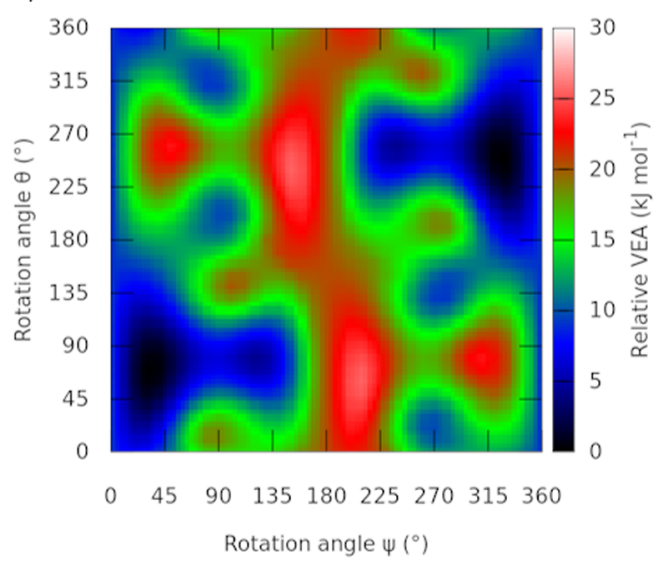

Figure 5. Frontier orbitals and effect of the three-dimensional rotation of an oriented electric field around the [4Fe4S] cluster. (a) Reduced, $S=1 /$ 2, broken-symmetry state 3; (b) reduced, $S=1 / 2$, broken-symmetry state 4; (c) oxidized, $\mathrm{mS}=0$, broken-symmetry state 4; (d) relative VEA with the most stable reduced broken-symmetry state.

relative VEA are the same for both the $[4 \mathrm{Fe} 4 \mathrm{~S}]$ and labile [4Fe4S] clusters, specifically approximately passing through a methyl group, the bonded sulfur and iron, and finally through the center of the cube and through the opposite sulfur atom. Since the maxima and minima observed for the VEA also influence electron-transfer reactions, it is not surprising that the observed field vectors (for maxima and minima) also follow the direction of the initial reductive electron transfer necessary for the formation of the 5 -deoxyadenosyl radical in radical SAM enzymes. ${ }^{90}$ As rSAM enzymes share the common feature of SAM bound to the cluster, this demonstrates how those enzymes may have evolved to arrange the active site to follow the minimum-energy pathway for this initial activation step for the enzymes. Additional electrostatic field effects initiated by other charged residues nearby can either support or reduce this effect.

\section{CONCLUSIONS}

We systematically investigated the effect of a rotating directed electric field on the stability and reactivity of biologically relevant iron-sulfur clusters. Applying DFT calculations on the model clusters, we used the VEA-represented as the energy difference between the oxidized and reduced states-as an indicator for the redox reactivity of the clusters. In both cases of the pure gas phase and calculations in implicit solvent, we could show that a directed electric field induced by two distant point charges significantly influences the stability and reactivity of the clusters. In agreement with molecular frontier orbital theory, the effects are significantly different for different 
a)
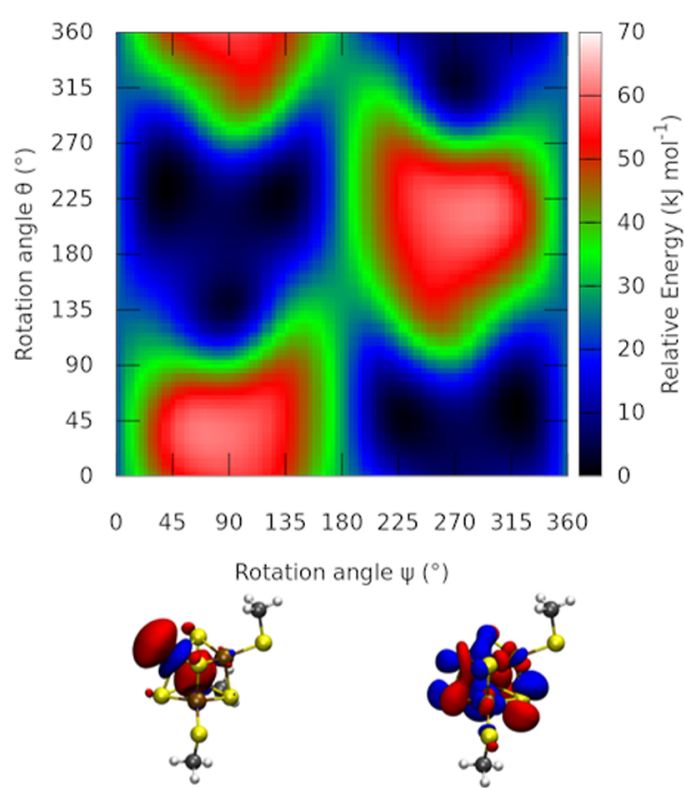

HOMO

c)
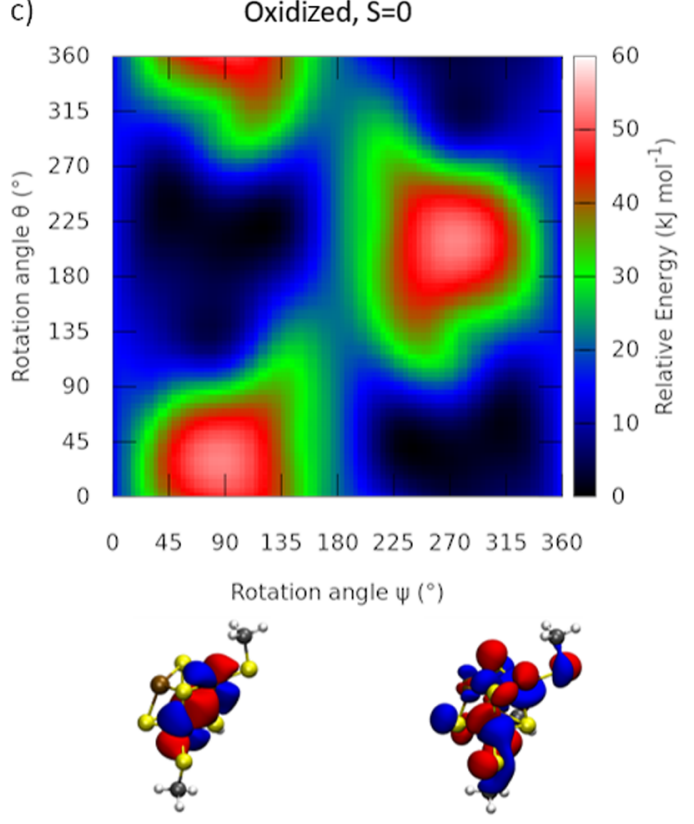

HOMO

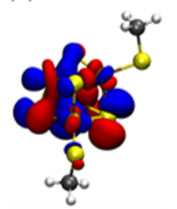

LUMO b)

\section{Minimum VEA \\ Maximum VEA}
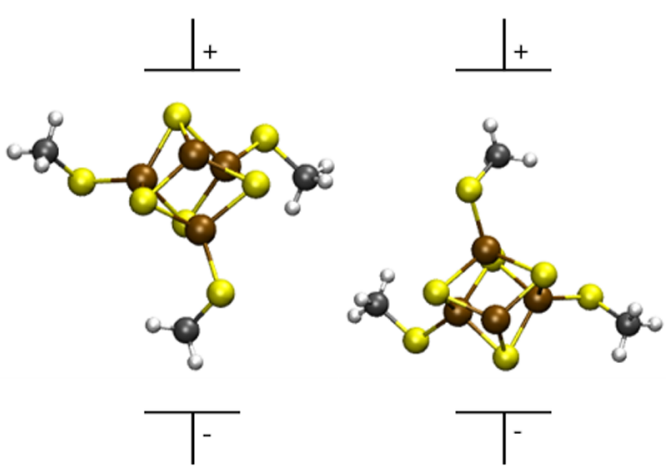

$\theta=140^{\circ} \psi=280^{\circ}$

$\theta=140^{\circ} \Psi=100^{\circ}$

d)

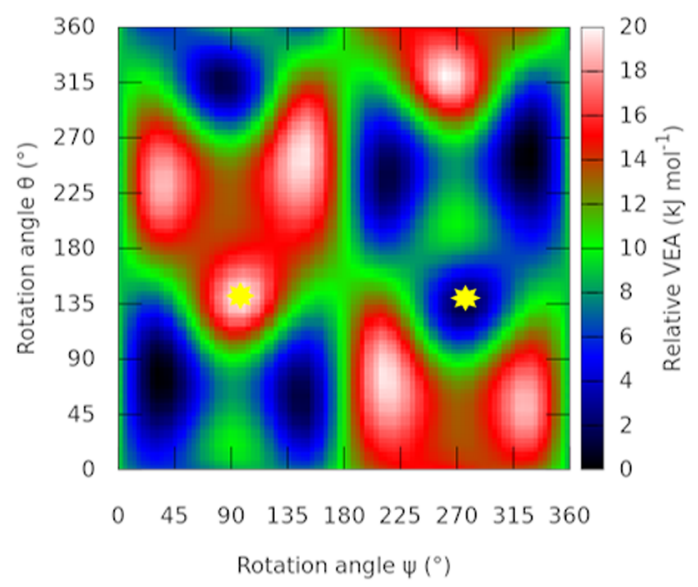

Figure 6. Frontier orbitals and effect of the three-dimensional rotation of an oriented electric field around the labile [4Fe4S] cluster. (a) Reduced, $S$ $=1 / 2$; (b) exemplary orientation of the field for the maximum and minimum values of the VEA, indicated in (d) by a yellow asterisk; (c) oxidized, $\mathrm{mS}=0$; (d) vertical electron affinity.

oxidation and broken-symmetry states. This leads to the observation that the most stable broken-symmetry state changes when reorientating an electric field around the [2Fe2S] cluster with significant implication for the reactivity of such clusters in heterogeneous environments such as enzyme active sites. Different orientations of the electric field had significantly different influences on the VEA and thus the reactivity of the clusters with a maximum effect of up to $25.5 \mathrm{~kJ}$ mol. $^{-1}$

The cubane clusters display more complex behavior, with it still being clear that the external electric field has a dramatic effect on the stability and reactivity of these clusters. The introduction of the COSMO environment alters the stability of the reduced cluster, stabilizing the favored broken-symmetry $1 / 2$ spin state relative to the other broken-symmetry state but also stabilizing the $9 / 2$ state relative to the most favored state, suggesting that in a protein environment, this stabilization effect is strengthened. The effects on the VEA are similar and in both cases dependent largely on whether the iron atoms experience unique force-field environments or similar ones, as shown in Figure 2D, where the field is rotated about the $\mathrm{Fe}-$ $\mathrm{Fe}$ axis and the changes in orientation are therefore the same for both iron atoms. Comparing the field with the orbital occupancy of the HOMO and LUMO of the clusters reinforces 
the hypothesis that the spatial location of electron density contributes significantly to the observed effects.

These strong anisotropic effects of the electric fields demonstrate their relevance for iron-sulfur clusters embedded in heterogeneous enzymatic environments. The impact of the field might explain how enzymes influence the redox reactivity of such clusters in a significant way. This systematic study reveals how these effects might be rationally explored and used as a powerful tool for enzyme engineering, where the external electric field would be generated by the surrounding residues, which can be mutated for the direct control of the properties of the iron-sulfur clusters.

While the model systems presented cannot reflect the complexity of the anisotropic charge distributions inside enzymatic active sites, the presented field strengths and strong directionality of the electric fields are comparable. ${ }^{51}$ Thus, the model systems offer a good reference on how changing the directionality of electric fields inside the enzymatic active sites can influence catalysis. In the next step, this information can be used for rational mutation studies with possible applications that might alter catalytic rates, substrate scope, and cluster stability (e.g., in oxygen-sensitive enzymes). Further work will focus on the nature and magnitude of these possible applications and how generalizable this approach is to other similar molecular groups in enzymes.

\section{ASSOCIATED CONTENT}

\section{(s) Supporting Information}

The Supporting Information is available free of charge at https://pubs.acs.org/doi/10.1021/acs.jcim.1c00791.

Further details on methods applied, detailed setup of the electric field calculations, evaluation of the electric field uniformity, and additional details of the results (PDF)

\section{AUTHOR INFORMATION}

\section{Corresponding Authors}

Jonathan D. Hirst - School of Chemistry, University of Nottingham, Nottingham NG7 2RD, U.K.; (1) orcid.org/ 0000-0002-2726-0983; Email: jonathan.hirst@ nottingham.ac.uk

Anna K. Croft - Department of Chemical and Environmental Engineering, Faculty of Engineering, University of Nottingham, Nottingham NG7 2RD, U.K.; $\odot$ orcid.org/ 0000-0001-5330-150X; Email: anna.croft@ nottingham.ac.uk

Christof M. Jäger - Department of Chemical and Environmental Engineering, Faculty of Engineering, University of Nottingham, Nottingham NG7 2RD, U.K.; (1) orcid.org/0000-0002-1802-1892;

Email: christof.jaeger@nottingham.ac.uk

\section{Author}

Samuel J. H. Gaughan - School of Chemistry and Department of Chemical and Environmental Engineering, Faculty of Engineering, University of Nottingham, Nottingham NG7 2RD, U.K.

Complete contact information is available at:

https://pubs.acs.org/10.1021/acs.jcim.1c00791

\section{Notes}

The authors declare no competing financial interest.
Structural coordinates, QM calculation input and truncated output files, and python scripts used for the automated procedures and analysis can be found in the online repository figshare (https://doi.org/10.6084/m9.figshare.14883615.v2).

\section{ACKNOWLEDGMENTS}

The authors thank the EPSRC Centre for Doctoral Training in Sustainable Chemistry (EP/L015633/1) for support, and they are grateful for access to the University of Nottingham High Performance Computing Facility. $\mathrm{JH}$ is supported by the Royal Academy of Engineering under the Chairs in Emerging Technologies scheme.

\section{REFERENCES}

(1) Huber, C.; Wächtershäuser, G. Activated Acetic Acid by carbon Fixation on (Fe,Ni)S Under Primordial Conditions. Science 1997, 276, 245-247.

(2) Beinert, H.; Holm, R. H.; Münck, E. Iron-Sulfur Clusters: Nature's Modular, Multipurpose Structures. Science 1997, 277, 653659.

(3) Beinert, H. Iron-Sulfur Proteins: Ancient Structures, Still Full of Surprises. J. Biol. Inorg Chem. 2000, 5, 2-15.

(4) Johnson, D. C.; Dean, D. R.; Smith, A. D.; Johnson, M. K. Structure, Function, and Formation of Biological Iron-Sulfur Clusters. Annu. Rev. Biochem. 2005, 74, 247-281.

(5) Mortenson, L. E.; Valentine, R. C.; Carnahan, J. E. An Electron Transport Factor from Clostridiumpasteurianum. Biochem. Biophys. Res. Commun. 1962, 7, 448-452.

(6) Glaser, T.; Hedman, B.; Hodgson, K. O.; Solomon, E. I. Ligand K-Edge X-ray Absorption Spectroscopy: A Direct Probe of LigandMetal Covalency. Acc. Chem. Res. 2000, 33, 859-868.

(7) Noodleman, L.; Case, D. A. Density-Functional Theory of Spin Polarization and Spin Coupling in Iron-Sulfur Clusters. In Iron-Sulfur Proteins; Advances in Inorganic Chemistry; Academic Press, Inc.: San Diego, CA, 1992; Vol. 38, pp 424-467.

(8) Lubitz, W.; Ogata, H.; Rüdiger, O.; Reijerse, E. Hydrogenases. Chem. Rev. 2014, 114, 4081-4148.

(9) Peters, J. W.; Stowell, M. H. B.; Soltis, S. M.; Finnegan, M. G.; Johnson, M. K.; Rees, D. C. Redox-Dependent Structural Changes in the Nitrogenase P-Cluster. Biochemistry 1997, 36, 1181-1187.

(10) Cheek, J.; Broderick, J. B. Adenosylmethionine-Dependent Iron-Sulfur Enzymes: Versatile Clusters in a Radical New Role. J. Biol. Inorg Chem. 2001, 6, 209-226.

(11) Broderick, J. B.; Duffus, B. R.; Duschene, K. S.; Shepard, E. M. Radical S-Adenosylmethionine Enzymes. Chem. Rev. 2014, 114, 4229-4317.

(12) Radical SAM Enzymes. In Methods in Enzymology; Bandarian, V., Ed.; Academic Press, Elsevier, 2018; Vol. 606.

(13) Jäger, C. M.; Croft, A. K. Anaerobic Radical Enzymes for Biotechnology. ChemBioEng Rev. 2018, 5, 143-162.

(14) Fugate, C. J.; Jarrett, J. T. Biotin synthase: Insights Into Radical-Mediated Carbon-Sulfur Bond Formation. Biochim. Biophys. Acta, Proteins Proteomics 2012, 1824, 1213-1222.

(15) Wood, Z. A.; Schröder, E.; Robin Harris, J.; Poole, L. B. Structure, Mechanism and Regulation of Peroxiredoxins. Trends Biochem. Sci. 2003, 28, 32-40.

(16) Arnér, E. S.; Holmgren, A. A Physiological Functions of Thioredoxin and Thioredoxin Reductase. Eur. J. Biochem. 2000, 267, 6102-6109.

(17) Tsukamoto, Y.; Fukushima, Y.; Hara, S.; Hisabori, T. Redox Control of the Activity of Phosphoglycerate Kinase in Synechocystis sp. PCC6803. Plant Cell Physiol. 2013, 54, 484-491.

(18) Gilbert, H. F. Redox Control of Enzyme Activities by Thiol/ Disulfide Exchange. In Methods in Enzymology; Academic Press, Elsevier, 1984; Vol. 107, pp 330-351. DOI: 10.1016/0076-6879(84) 07022-1 
(19) Richter, A. S.; Grimm, B. Thiol-Based Redox Control of Enzymes Involved in the Tetrapyrrole Biosynthesis Pathway in Plants. Front. Plant Sci. 2013, 4, 371.

(20) Hitaishi, V.; Clement, R.; Bourassin, N.; Baaden, M.; De Poulpiquet, A.; Sacquin-Mora, S.; Ciaccafava, A.; Lojou, E. Controlling Redox Enzyme Orientation at Planar Electrodes. Catalysts 2018, 8, 192.

(21) Caceres, T. B.; Price, O.; Morales, Y.; Hevel, J. Redox Control of PRMT1 Substrate Specificity. FASEB J. 2017, 31, 765-811.

(22) Bonifacio, A.; Millo, D.; Keizers, P. H. J.; Boegschoten, R.; Commandeur, J. N. M.; Vermeulen, N. P. E.; Gooijer, C.; van der Zwan, G. Active-Site Structure, Binding and Redox Activity of the Heme-Thiolate Enzyme CYP2D6 Immobilized on Coated Ag Electrodes: a Surface-Enhanced Resonance Raman Scattering Study. J. Biol. Inorg Chem. 2008, 13, 85-96.

(23) Skryhan, K.; Cuesta-Seijo, J. A.; Nielsen, M. M.; Marri, L.; Mellor, S. B.; Glaring, M. A.; Jensen, P. E.; Palcic, M. M.; Blennow, A. The Role of Cysteine Residues in Redox Regulation and Protein Stability of Arabidopsis thaliana Starch Synthase 1. PLoS One 2015, 10, No. e0136997.

(24) Léger, C.; Bertrand, P. Direct Electrochemistry of Redox Enzymes as a Tool for Mechanistic Studies. Chem. Rev. 2008, 108, 2379-2438.

(25) Gates, A. J.; Kemp, G. L.; To, C. Y.; Mann, J.; Marritt, S. J.; Mayes, A. G.; Richardson, D. J.; Butt, J. N. The Relationship Between Redox Enzyme Activity and Electrochemical Potential-Cellular and Mechanistic Implications from Protein Film Electrochemistry. Phys. Chem. Chem. Phys. 2011, 13, 7720-7731.

(26) Elliott, S. J.; Léger, C.; Pershad, H. R.; Hirst, J.; Heffron, K.; Ginet, N.; Blasco, F.; Rothery, R. A.; Weiner, J. H.; Armstrong, F. A. Detection and Interpretation of Redox Potential Optima in the Catalytic Activity of Enzymes. Biochim. Biophys. Acta 2002, 1555, 5459.

(27) Tran, K. N.; Niu, S.; Ichiye, T. Reduction potential calculations of the Fe-S clusters in Thermus thermophilus respiratory complex I. J. Comput. Biol. 2019, 40, 1248-1256.

(28) Bak, D. W.; Elliott, S. J. Alternative FeS Cluster Ligands: Tuning Redox Potentials and Chemistry. Curr. Opin. Chem. Biol. 2014, 19, 50-58.

(29) Zhang, L.; Cui, H.; Zou, Z.; Garakani, T. M.; NovoaHenriquez, C.; Jooyeh, B.; Schwaneberg, U. Directed Evolution of a Bacterial Laccase (CueO) for Enzymatic Biofuel Cells. Angew. Chem., Int. Ed. 2019, 58, 4562-4565.

(30) Sandford, C.; Edwards, M. A.; Klunder, K. J.; Hickey, D. P.; Li, M.; Barman, K.; Sigman, M. S.; White, H. S.; Minteer, S. D. A Synthetic Chemist's Guide to Electroanalytical Tools for Studying Reaction Mechanisms. Chem. Sci. 2019, 10, 6404-6422.

(31) Hannemann, F.; Guyot, A.; Zöllner, A.; Müller, J. J.; Heinemann, U.; Bernhardt, R. The Dipole Moment of the Electron Carrier Adrenodoxin is not Critical for Redox Partner Interaction and Electron Transfer. J. Inorg. Biochem. 2009, 103, 997-1004.

(32) Ikeda, T.; Kano, K. An Electrochemical Approach to the Studies of Biological Redox Reactions and their Applications to Biosensors, Bioreactors, and Biofuel cells. J. Biosci. Bioeng. 2001, 92, $9-18$.

(33) Warshel, A.; Aqvist, J. Electrostatic Energy and Macromolecular Function. Annu. Rev. Biophys. Biophys. Chem. 1991, 20, 267-298.

(34) Sheinerman, F.; Norel, R.; Honig, B. Electrostatic aspects of protein-protein interactions. Curr. Opin. Struct. Biol. 2000, 10, 153159.

(35) Hanoian, P.; Liu, C. T.; Hammes-Schiffer, S.; Benkovic, S. Perspectives on Electrostatics and Conformational Motions in Enzyme Catalysis. Acc. Chem. Res. 2015, 48, 482-489.

(36) Warshel, A.; Sharma, P. K.; Kato, M.; Xiang, Y.; Liu, H.; Olsson, M. H. M. Electrostatic Basis for Enzyme Catalysis. Chem. Rev. 2006, 106, 3210-3235.

(37) Fried, S. D.; Boxer, S. G. Electric Fields and Enzyme Catalysis. Annu. Rev. Biochem. 2017, 86, 387-415.
(38) Warshel, A. Electrostatic Origin of the Catalytic Power of Enzymes and the Role of Preorganized Active Sites. J. Biol. Chem. 1998, 273, 27035-27038.

(39) Morgenstern, A.; Jaszai, M.; Eberhart, M. E.; Alexandrova, A. N. Quantified Electrostatic Preorganization in Enzymes Using the Geometry of the Electron Charge Density. Chem. Sci. 2017, 8, $5010-5018$.

(40) Fuller, J.; Wilson, T. R.; Eberhart, M. E.; Alexandrova, A. N. Charge Density in Enzyme Active Site as a Descriptor of Electrostatic Preorganization. J. Chem. Inf. Model. 2019, 59, 2367-2373.

(41) Náray-Szabó, G. Electrostatic Catalysis in Enzymes. J. Mol. Catal. 1988, 47, 281-287.

(42) Warshel, A. Computer Simulations of Enzyme Catalysis: Methods, Progress, and Insights. Annu. Rev. Biophys. Biomol. Struct. 2003, 32, 425-443.

(43) Warshel, A.; Sharma, P. K.; Kato, M.; Parson, W. W. Modeling Electrostatic Effects in Proteins. Biochim. Biophys. Acta 2006, 1764, $1647-1676$.

(44) Nielsen, J. E.; Beier, L.; Otzen, D.; Borchert, T. V.; Frantzen, H. B.; Andersen, K. V.; Svendsen, A. Electrostatics in the active site of an alpha-amylase. Eur. J. Biochem. 1999, 264, 816-824.

(45) Yang, Z.; Liu, F.; Steeves, A. H.; Kulik, H. J. Quantum Mechanical Description of Electrostatics Provides a Unified Picture of Catalytic Action Across Methyltransferases. J. Phys. Chem. Lett. 2019, 10, 3779-3787.

(46) Suess, C. J.; Martins, F. L.; Croft, A. K.; Jäger, C. M. Radical Stabilization Energies for Enzyme Engineering: Tackling the Substrate Scope of the Radical Enzyme QueE. J. Chem. Inf. Model. 2019, 59, $5111-5125$

(47) Gilson, M. K.; Honig, B. H. Calculation of Electrostatic Potentials in an Enzyme Active Site. Nature 1987, 330, 84-86.

(48) Eun, C.; Kekenes-Huskey, P. M.; Metzger, V. T.; McCammon, J. A. A model Study of Sequential Enzyme Reactions and Electrostatic Channeling. J. Chem. Phys. 2014, 140, 105101.

(49) Wade, R. C.; Gabdoulline, R. R.; Ludemann, S. K.; Lounnas, V. Electrostatic steering and ionic tethering in enzyme-ligand binding: Insights from simulations. Proc. Natl. Acad. Sci. U.S.A. 1998, 95, 5942-5949.

(50) Fried, S. D.; Bagchi, S.; Boxer, S. G. Extreme Electric Fields Power Catalysis in the Active Site of Ketosteroid Isomerase. Science 2014, 346, 1510-1514.

(51) Shaik, S.; Mandal, D.; Ramanan, R. Oriented Electric Fields as Future Smart Reagents in Chemistry. Nat. Chem. 2016, 8, 10911098 .

(52) Orozco-Gonzalez, Y.; Kabir, M. P.; Gozem, S. Electrostatic Spectral Tuning Maps for Biological Chromophores. J. Phys. Chem. B 2019, 123, 4813-4824.

(53) Prah, A.; Frančišković, E.; Mavri, J.; Stare, J. Electrostatics as the Driving Force Behind the Catalytic Function of the Monoamine Oxidase A Enzyme Confirmed by Quantum Computations. ACS Catal. 2019, 9, 1231-1240.

(54) Bhave, D. P.; Han, W.-G.; Pazicni, S.; Penner-Hahn, J. E.; Carroll, K. S.; Noodleman, L. Geometric and Electrostatic Study of the [4Fe-4S] Cluster of Adenosine-5'-Phosphosulfate Reductase from Broken Symmetry Density Functional Calculations and Extended Xray Absorption Fine Structure Spectroscopy. Inorg. Chem. 2011, 50, 6610-6625.

(55) Noodleman, L. Valence Bond Description of Antiferromagnetic Coupling in Transition Metal Dimers. J. Chem. Phys. 1981, 74, 57375743 .

(56) Shao, Y.; Gan, Z.; Epifanovsky, E.; Gilbert, A. T. B.; Wormit, M.; Kussmann, J.; Lange, A. W.; Behn, A.; Deng, J.; Feng, X.; Ghosh, D.; Goldey, M.; Horn, P. R.; Jacobson, L. D.; Kaliman, I.; Khaliullin, R. Z.; Kuś, T.; Landau, A.; Liu, J.; Proynov, E. I.; Rhee, Y. M.; Richard, R. M.; Rohrdanz, M. A.; Steele, R. P.; Sundstrom, E. J., III; Woodcock, H. L.; Zimmerman, P. M.; Zuev, D.; Albrecht, B.; Alguire, E.; Austin, B.; Beran, G. J. O.; Bernard, Y. A.; Berquist, E.; Brandhorst, K.; Bravaya, K. B.; Brown, S. T.; Casanova, D.; Chang, C.-M.; Chen, Y.; Chien, S. H.; Closser, K. D.; Crittenden, D. L.; Diedenhofen, M., 
Jr.; DiStasio, R. A.; Do, H.; Dutoi, A. D.; Edgar, R. G.; Fatehi, S.; Fusti-Molnar, L.; Ghysels, A.; Golubeva-Zadorozhnaya, A.; Gomes, J.; Hanson-Heine, M. W. D.; Harbach, P. H. P.; Hauser, A. W.; Hohenstein, E. G.; Holden, Z. C.; Jagau, T.-C.; Ji, H.; Kaduk, B.; Khistyaev, K.; Kim, J.; Kim, J.; King, R. A.; Klunzinger, P.; Kosenkov, D.; Kowalczyk, T.; Krauter, C. M.; Lao, K. U.; Laurent, A. D.; Lawler, K. V.; Levchenko, S. V.; Lin, C. Y.; Liu, F.; Livshits, E.; Lochan, R. C.; Luenser, A.; Manohar, P.; Manzer, S. F.; Mao, S.-P.; Mardirossian, N.; Marenich, A. V.; Maurer, S. A.; Mayhall, N. J.; Neuscamman, E.; Oana, C. M.; Olivares-Amaya, R.; O’Neill, D. P.; Parkhill, J. A.; Perrine, T. M.; Peverati, R.; Prociuk, A.; Rehn, D. R.; Rosta, E.; Russ, N. J.; Sharada, S. M.; Sharma, S.; Small, D. W.; Sodt, A.; Stein, T.; Stück, D.; Su, Y.-C.; Thom, A. J. W.; Tsuchimochi, T.; Vanovschi, V.; Vogt, L.; Vydrov, O.; Wang, T.; Watson, M. A.; Wenzel, J.; White, A.; Williams, C. F.; Yang, J.; Yeganeh, S.; Yost, S. R.; You, Z.-Q.; Zhang, I. Y.; Zhang, X.; Zhao, Y.; Brooks, B. R.; Chan, G. K. L.; Chipman, D. M.; Cramer, C. J., III; Goddard, W. A.; Gordon, M. S.; Hehre, W. J.; Klamt, A., III; Schaefer, H. F.; Schmidt, M. W.; Sherrill, C. D.; Truhlar, D. G.; Warshel, A.; Xu, X.; Aspuru-Guzik, A.; Baer, R.; Bell, A. T.; Besley, N. A.; Chai, J.-D.; Dreuw, A.; Dunietz, B. D.; Furlani, T. R.; Gwaltney, S. R.; Hsu, C.-P.; Jung, Y.; Kong, J.; Lambrecht, D. S.; Liang, W.; Ochsenfeld, C.; Rassolov, V. A.; Slipchenko, L. V.; Subotnik, J. E.; Van Voorhis, T.; Herbert, J. M.; Krylov, A. I.; Gill, P. M. W.; Head-Gordon, M. Advances in Molecular Quantum Chemistry Contained in the Q-Chem 4 Program Package. Mol. Phys. 2015, 113, 184-215.

(57) Carvalho, A. T. P.; Swart, M. Electronic Structure Investigation and Parametrization of Biologically Relevant Iron-Sulfur Clusters. J. Chem. Inf. Model. 2014, 54, 613-620.

(58) Swart, M.; Groenhof, A. R.; Ehlers, A. W.; Lammertsma, K. Validation of Exchange-Correlation Functionals for Spin States of Iron Complexes. J. Phys. Chem. A 2004, 108, 5479-5483.

(59) Swart, M.; Ehlers, A. W.; Lammertsma, K. Performance of the OPBE Exchange-Correlation Functional. Mol. Phys. 2004, 102, 24672474.

(60) Handy, N. C.; Cohen, A. J. Left-Right Correlation Energy. Mol. Phys. 2001, 99, 403-412.

(61) Perdew, J. P.; Burke, K.; Ernzerhof, M. Generalized Gradient Approximation Made Simple. Phys. Rev. Lett. 1996, 77, 3865.

(62) Van Lenthe, E.; Baerends, E. J. Optimized Slater-type basis sets for the elements 1-118. J. Comput. Chem. 2003, 24, 1142-1156.

(63) Chong, D. P.; Van Lenthe, E.; Van Gisbergen, S.; Baerends, E. J. Even-Tempered Slater-Type Orbitals Revisited: From Hydrogen to Krypton. J. Comput. Chem. 2004, 25, 1030-1036.

(64) Chong, D. P. Augmenting Basis Set for Time-Dependent Density Functional Theory Calculation of Excitation Energies: SlaterType Orbitals for Hydrogen to Krypton. Mol. Phys. 2005, 103, 749761.

(65) Harris, T. V.; Szilagyi, R. K. Iron-sulfur bond covalency from electronic structure calculations for classical iron-sulfur clusters. $J$. Comput. Chem. 2014, 35, 540-552.

(66) Szilagyi, R. K.; Winslow, M. A. On the accuracy of density functional theory for iron-sulfur clusters. J. Comput. Chem. 2006, 27, 1385-1397.

(67) Harris, T. V.; Szilagyi, R. K. Protein Environmental Effects on Iron-Sulfur Clusters: A Set of Rules for Constructing Computational Models for Inner and Outer Coordination Spheres. J. Comput. Chem. 2016, 37, 1681-1696.

(68) Swart, M. Accurate Spin-State Energies for Iron Complexes. J. Chem. Theory Comput. 2008, 4, 2057-2066.

(69) Güell, M.; Luis, J. M.; Solà, M.; Swart, M. Importance of the Basis Set for the Spin-State Energetics of Iron Complexes. J. Phys. Chem. A 2008, 112, 6384-6391.

(70) Klamt, A.; Schüürmann, G. COSMO A New Approach to Dielectric Screening in Solvents With Explicit Expressions for the Screening Energy and its Gradient. J. Chem. Soc., Perkin Trans. 2 1993, 2, 799-805.

(71) Gilson, M. K.; Honig, B. H. The Dielectric Constant of a Folded Protein. Biopolymers 1986, 25, 2097-2119.
(72) Sharp, K. A.; Honig, B. Electrostatic Interactions in Macromolecules: Theory and Applications. Annu. Rev. Biophys. Biophys. Chem. 1990, 19, 301-332.

(73) Noodleman, L.; Baerends, E. J. Electronic structure, magnetic properties, ESR, and optical spectra for 2-iron ferredoxin models by LCAO-X.alpha. valence bond theory. J. Am. Chem. Soc. 1984, 106, 2316-2327.

(74) Noodleman, L.; Peng, C. Y.; Case, D. A.; Mouesca, J.-M. Orbital Interactions, Electron Delocalization and Spin Coupling in Iron-Sulfur Clusters. Coord. Chem. Rev. 1995, 144, 199-244.

(75) Emelyanova, N. S.; Poleshchuk, O. Kh.; Sanina, N. A.; Aldoshin, S. M. Quantum Chemical Modelling of Ligand Substitution in Cationic Nitrosyl Complexes. Russ. Chem. Bull. 2014, 63, 10881094.

(76) Sandala, G. M.; Hopmann, K. H.; Ghosh, A.; Noodleman, L. Calibration of DFT Functionals for the Prediction of 57Fe Mössbauer Spectral Parameters in Iron-Nitrosyl and Iron-Sulfur Complexes: Accurate Geometries Prove Essential. J. Chem. Theory Comput. 2011, 7, 3232-3247.

(77) Jensen, K. P.; Ooi, B.-L.; Christensen, H. E. M. Accurate Computation of Reduction Potentials of $4 \mathrm{Fe}-4 \mathrm{~S}$ Clusters Indicates a Carboxylate Shift in Pyrococcus furiosus Ferredoxin. Inorg. Chem. 2007, 46, 8710-8716.

(78) Han, W.-G.; Liu, T.; Lovell, T.; Noodleman, L. Active Site Structure of Class I Ribonucleotide Reductase Intermediate X: A Density Functional Theory Analysis of Structure, Energetics, and Spectroscopy. J. Am. Chem. Soc. 2005, 127, 15778-15790.

(79) Maiocco, S. J.; Walker, L. M.; Elliott, S. J. Determining Redox Potentials of the Iron-Sulfur Clusters of the AdoMet Radical Enzyme Superfamily. In Methods in Enzymology; Bandarian, V., Ed.; Academic Press, 2018, pp 319-339. DOI: 10.1016/bs.mie.2018.06.002

(80) Miranda-Quintana, R. A.; Martínez González, M.; Ayers, P. W. Electronegativity and Redox Reactions. Phys. Chem. Chem. Phys. 2016, $18,22235-22243$.

(81) Parr, R. G.; Szentpály, L. v.; Liu, S. Electrophilicity Index. J. Am. Chem. Soc. 1999, 121, 1922-1924.

(82) Moens, J.; Roos, G.; Jaque, P.; De Proft, F.; Geerlings, P. Can Electrophilicity Act as a Measure of the Redox Potential of First-Row Transition Metal Ions? Chem. Eur J. 2007, 13, 9331-9343.

(83) Chattaraj, P. K.; Giri, S. Electrophilicity index within a conceptual DFT framework. Annu. Rep. Prog. Chem., Sect. C: Phys. Chem. 2009, 105, 13-39.

(84) Moens, J.; Jaque, P.; De Proft, F.; Geerlings, P. The Study of Redox Reactions on the Basis of Conceptual DFT Principles: EEM and Vertical Quantities. J. Phys. Chem. A 2008, 112, 6023-6031.

(85) Roos, G.; Geerlings, P.; Messens, J. Enzymatic Catalysis: The Emerging Role of Conceptual Density Functional Theory. J. Phys. Chem. B 2009, 113, 13465-13475.

(86) Sharma, S.; Sivalingam, K.; Neese, F.; Chan, G. K.-L. LowEnergy Spectrum of Iron-Sulfur Clusters Directly from Many-Particle Quantum Mechanics. Nat. Chem. 2014, 6, 927-933.

(87) Gillum, W. O.; Frankel, R. B.; Foner, S.; Holm, R. H. Synthetic Analogues of the Active Sites of Iron-Sulfur Proteins. XIII. Further Electronic Structural Relationships between the Analogues [Fe2S2(SR)4]2- and the Active Sites of Oxidised 2Fe-2S Proteins. Inorg. Chem. 1976, 15, 1095-1100.

(88) Teo, R. D.; Rousseau, B. J. G.; Smithwick, E. R.; Di Felice, R.; Beratan, D. N.; Migliore, A. Charge Transfer between [4Fe4S] Proteins and DNA Is Unidirectional: Implications for Biomolecular Signaling. Chemistry 2019, 5, 122-137.

(89) Cervantes-Salguero, K.; Seminario, J. M. Structure and Energetics of Small Iron Clusters. J. Mol. Model. 2012, 18, 40434052.

(90) Nicolet, Y.; Amara, P.; Mouesca, J.-M.; Fontecilla-Camps, J. C. Unexpected Electron Transfer Mechanism Upon AdoMet Cleavage in Radical SAM Proteins. Proc. Natl. Acad. Sci. U.S.A. 2009, 106, 1486714871. 